\title{
Nuclear Physics Roundup
}

\section{US: Readjustments}

The renaissance of nuclear physics in the USA is meeting some resistance with the announcement that a committee of the Department of Energy (which funds most of the nuclear science in the USA) will propose in July 1990 which one of three facilities it will close down to allow the reassignment of \$US 2-5 million of operating funds. The facilities are the 88 inch cyclotron at Berkeley, the Atlas facility at Argonne National Laboratory and the Holifield Heavy Ion Research Facility at Oak Ridge.

It is likely that the Nuclear Science Advisory Committee, whose principle recommendation in a 1988 report urged the setting up of at least one nuclear theory centre (see page 113), will meet to analyze the implications of any decision to cut back existing facilities for nuclear physics.

Meanwhile, construction of CEBAF (see Figure) should now finish in 1994, funds for the proposed Relativistic Heavy lon Collider are included in President Bush's 1991 budget, and there may be a green light for the Canadian KAON particle beam 'factory' this year - although this is starting to seem unlikely - for which a US contribution has been proposed.

\section{EC: LSF Ending}

Seven facilities have been preselected from the 90 proposals made in response to the last call for proposals (March 1989) for the LARGE SCALE FACILITIES programme of the CEC's current Framework Programme. Three are nuclear science centres - Hahn Meitner, Risø and Saclay. Second, more detailed proposals are being submitted at the present time as the basis for a final selection and a call for tenders that will be announced in the Autumn. For budget reasons however, the programme's funds - which are intended to help make national facilities more accessible to researchers in other countries - will not be available until 1992.

The LSF Programme or an equivalent is not included in the CEC's new Framework Programme that was approved by the Commission recently. Unless the proposals are modified by the Council of Ministers following discussions in Parliament, the present round of LSF grants may be the last.

The Hahn Meitner Institute meanwhile remains in a difficult position because an upgrade, started in 1985 , to increase the thermal neutron flux of the Institute's reactor by a factor of 10 is complete, but permission to restart the reactor has not been given. The regulating authority, which belongs to the Berlin Senate, is expected to announce its decision in July. The problem has been that the US Department of Energy cannot now authorize the transport of spent fuel across the US to a reprocessing plant. An alternative reprocessor - Dounreay - was found but the authority claimed that Dounreay's and German emis-

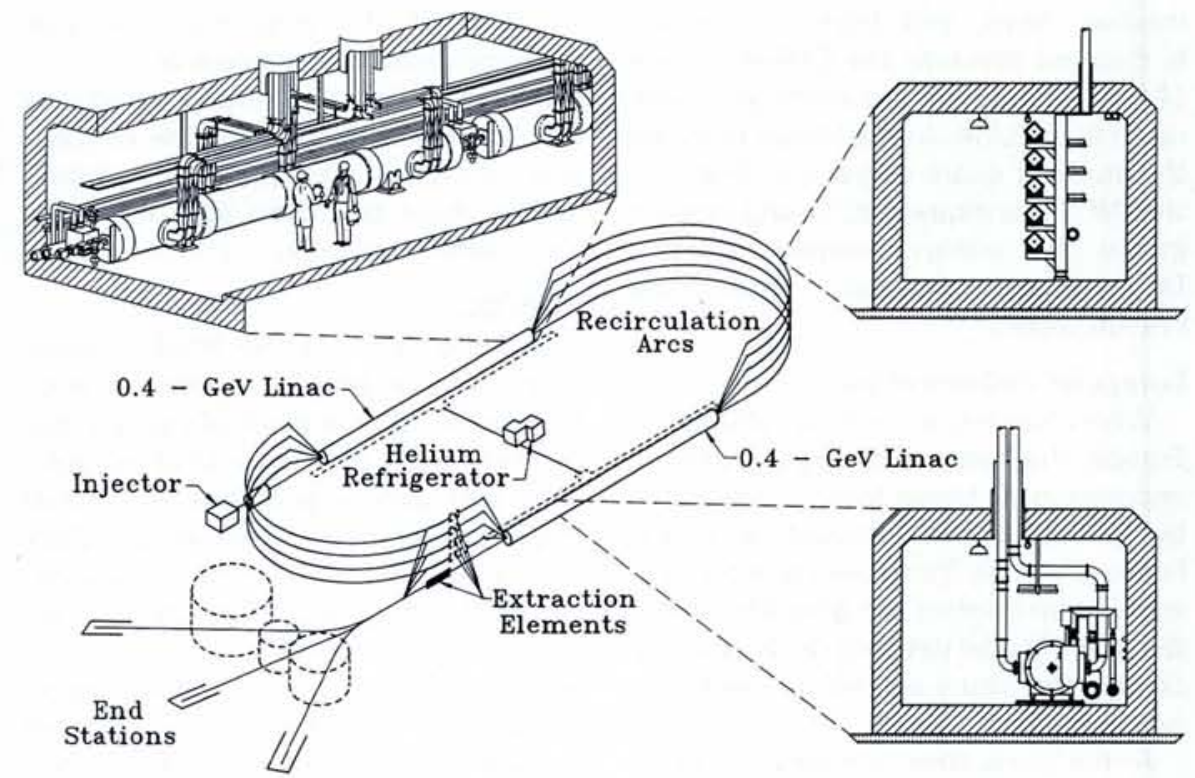

sion standards are not compatible; and that reprocessed material could be diverted to military uses. The British Ambassador to Germany recently rejected these claims.

The Hahn Meitner Institute emphasizes that the reactor's beams will be used entirely for scattering work by condensed matter physicists and the like. The Institute also possess an accelerator that provides experimental facilities for about 30 scientists and 30 visitors but this is not included in the LSF proposal.

\section{Eastern Europe: How to Progress}

Nuclear physics has always been an active field of research in many countries in eastern Europe because relatively modest equipment produced significant results. Several strong centres exist in Warsaw, Prague and elsewhere. However, as the report by Professor Sick emphasizes (see page 111), nuclear physics has been changing: new equipment is needed, including European scale facilities. Science budgets are being cut and in spite of considerable goodwill on both sides countries, there are limits. Romania for example, has never been able to fully recover from an earthquake that damaged its Van de Graaff accelerator several years ago.

Nevertheless, some eastern European countries are actively exploring the possibility of upgrading facilities by acquiring equipment that is being replaced in western laboratories.

It is too early to speculate upon the success of these initiatives, which will probably be discussed at the special EPS meeting on East-West issues, initiated by the Netherlands' Physical Society, to be held after the General Conference in Amsterdam. An organizing committee sponsored by the Dutch society met recently to work out the programme.
An illustration of the $4 \mathrm{GeV}$ Continuous Electron Beam Accelerator Facility (CEBAF) under construction at Newport News, Virginia, USA. A recent French audit of nuclear physics (see page 111) made the case for a similar but higher energy machine.

A System for Doing Mathematics by Computer

A Wolfram Research Inc. product

$\square$ Numerics - Works with numbers of arbitrary magnitude and precision.

$\square$ Symbolics - Encyclopaedia of mathematical functions and operations used in arithmetic, algebra and analysis.

Procedural, functional and mathematical programming.

$\square$ Graphics - 2D, 3D and animated PostScript graphics.

Text processing - Fully interactive reports and textbooks.

$\square$ Runs on - MS-DOS based computers; Macintosh, Apollo, Hewlett Packard, IBM AIX/RT, MIPS, Silicon Graphics, Sony, Sun, VAX.

Now available in Europe from:

MathSoft Overseas, Inc.

POB 641, 1211 Geneva 3, Switzerland Tel. $++41(22) 465260$

Fax $++41(22) 465939$

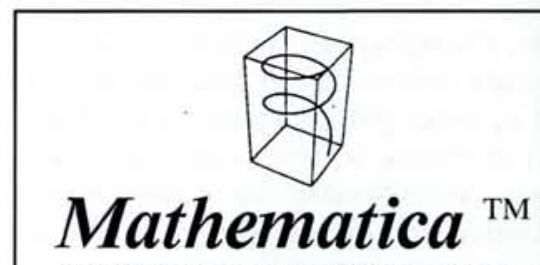

